\title{
Knowledge, Attitudes and Practices towards Hypertension among Hypertensive Patients in Rural Area, Tanvè (Benin)
}

\author{
Nadège Corine Yessito Houehanou ${ }^{1,2, *}$, Ariyoh Salimanou Amidou ${ }^{2}$, Arnaud Joël Djidjoho Sonou ${ }^{3}$, \\ Gwladys Gbaguidi ${ }^{2,4}$, Latifath Ibouraïma ${ }^{1}$, Philippe Lacroix ${ }^{4,5}$, Dismand Houinato ${ }^{2,4}$ \\ ${ }^{1}$ National School for Training of Senior Technicians in Public Health and Epidemiological Surveillance (ENATSE), Parakou \\ University, Parakou, Benin \\ ${ }^{2}$ Laboratory of Chronic and Neurological Diseases Epidemiology, Abomey-Calavi University, Cotonou, Benin \\ ${ }^{3}$ University Cardiology Clinic, CNHU HKM, Cotonou, Benin \\ ${ }^{4}$ INSERM UMR1094, Tropical Neuroepidemiology, University of Limoges, Limoges, France \\ ${ }^{5}$ Department of Thoracic \& Cardiovascular Surgery and Vascular Medicine, Dupuytren University Hospital, Limoges, France
}

Received March 13, 2020; Revised May 1, 2020; Accepted May 13, 2020

Copyright $\bigcirc 2020$ by authors, all rights reserved. Authors agree that this article remains permanently open access under the terms of the Creative Commons Attribution License 4.0 International License

\begin{abstract}
Hypertension mortality could be reduced by compliance with treatments and hygienic rules. The study aimed to assess the knowledge, attitudes and practices (KAPs) towards hypertension among hypertensive patients at Tanvè (Benin) in 2018. Materials and Methods: This was a cross-sectional study. It included, people aged 25 and over, followed in Tanvè Health Study and screened hypertensive during the 2017 visit. An individual interview was used for the data collection in 2018. The evaluation of the KAPs was made by questions with two optional answers, marked 0 or 1: 24 for knowledge, 8 for attitudes and 12 for practices. The level was rated good when the score was $\geq 3$ rd quartile of the theoretical score. Results: A total of 380 people were surveyed, $67.9 \%$ of whom were women; the mean age was $52.4 \pm 16.5$ years. Among them, 22.6\% had a good level of knowledge and $89.7 \%$ had good attitudes. Only $50.1 \%$ of the respondents were aware of their history of hypertension. Few of them (5.2\%) had good practices towards hypertension. Conclusion: This study shows a low level of knowledge and practices towards hypertension. Interventions for the therapeutic education of hypertensive patients would be effective within the target population.
\end{abstract}

Keywords Knowledge, Attitudes and Practices, Hypertensive Patients, Benin

\section{Introduction}

Hypertension constitutes a major public health concern worldwide, due to its high frequency and mortality [1-3]. It is a long-term condition, often asymptomatic, which is revealed by cardiovascular and renal complications [4]. More than a quarter of the world's adult population is hypertensive, and this proportion is expected to reach $30 \%$ by 2025 , if the response is not effective [1].

Despite the availability of treatments, hypertension is inadequately treated and controlled [3, 5-7]. The poor prognosis for uncontrolled hypertension can be avoided by regular medical monitoring and a healthy lifestyle. Compliance with hygiene rules and drugs by hypertensive patients require good knowledge and a good perception of the hypertension associated risk.

Hypertension affects around a third of adults in sub-Saharan Africa [8]. In many of these countries, most patients fully finance care and purchase of drugs in a low socioeconomic context [8]. Several of them have already developed at least one hypertensive complication, and have associated risk factors such as obesity and dyslipidemia $[9,10]$. This situation shows the severity of hypertension in sub-Saharan African countries and the importance of blood pressure normalization.

In 2015, the prevalence of hypertension in Benin was estimated at $25.9 \%$ nationally and $15.9 \%$ in the district of Zou [11]. According to a study performed in 2016 among hypertensive patients monitored in a peripheral health center of Benin, the level of knowledge relating to hypertension was poor. In addition, less than half of the 
hypertensive patients enrolled had correct diet and regular physical activity; about three-quarters were not receiving any medical treatment [12].

A cohort study on cardiovascular diseases is ongoing since February 2015 in the villages of Tanvè and Dékanmè, in central Benin, district of Zou. It includes adults residents aged 25 years and over [13]. A screening for hypertension was carried out at inclusion visit in 2015 . The blood pressure is measured annually during the follow-up visit [13].

\section{Objectives}

The objective of this study was to assess the knowledge, attitudes and practices (KAPs) towards hypertension among hypertensive patients in Tanvè in 2018.

\section{Materials and Methods}

\subsection{Frame}

The study took place in central Benin, in the villages of Tanvè and Dékanmè. These are two neighbouring villages located in the area of Tanvè, $10 \mathrm{~km}$ from Abomey town and $150 \mathrm{~km}$ from Cotonou (economic capital of Benin). The adult population is approximately 2000. The main activity is agriculture and the main language is "Fon". Christian religions and voodoo cults are more practiced. Tanvè village has a public health center comprising a dispensary managed by a nurse and a maternity unit managed by a midwife. The Abomey departmental hospital is the region's benchmark hospital where a cardiologist works. There is no universal health insurance system. The vast majority of care and medicines are funded by the individuals themselves and their families. Traditional medicine occupies an important place in disease management.

The Tanvè health center has electronic blood pressure monitors, glucometers, scales, measuring rods for monitoring patients. There is no laboratory for biological analysis on venous blood. A general practitioner recruited by the TAHES project provides two free medical consultation sessions per month at the dispensary. There is a small pharmacy in the health center and several private pharmacies in Abomey. Generic drugs available for the hypertension management at Tanvè health center are: amlodipine, nifedipine (calcium channels blockers); hydrochlorothiazide (diuretic) and alpha-methyldopa (central acting antihypertensive drug). The average transfer prices for a monthly treatment vary between 1 and 10 USD dollars depending on the prescriptions.

\subsection{Design, Population and Data Collection}

It was a descriptive cross-sectional study. It included people aged 25 and over, participating in TAHES (Tanvè Health Study), having had raised blood pressure or taking a treatment for hypertension during the 2017 visit, and having given their written consent. Patients unable to answer questions due to any disability, those who were absent after two unsuccessful visits, and pregnant women were not included.

The data were collected from October 1 to December 1, 2018. The data collection techniques used were: face-to-face structured individual interview with the respondent and direct observation (measurement of anthropometric parameters). A standardized questionnaire was administered to participants. The questionnaire was written in French and then translated into the Fon language, the main language of the locality. The questionnaire comprised sociodemographic information and questions about KAPs towards hypertension. It was tested and readjusted before the investigation began. The interview was carried out at participant's home, either in French or in "Fon" by two trained investigators (one community worker and one student in public health). The questionnaire was filled in the French form. Then, weight, height and blood pressure were measured. Three consecutive measurements of blood pressure were taken, after 10 minutes of rest, in sitting position, on left arm. The blood pressure was the average of the last two measurements.

\subsection{KAPs Evaluation}

KAPs were assessed by series of questions with two optional answers marked 0 or 1 . The level was rated good when the score is $\geq 3$ rd quartile of theoretical score. The knowledges were assessed by 24 questions and were classified as good when the score was $\geq 18$. The attitudes were assessed by 8 questions and were classified as good when the score was $\geq 6$. The practices were assessed by 12 questions and were classified as good when the score was $\geq 9$.

\subsection{Ethic Consideration}

The favorable opinion of the educational committee of ENATSE (National school for training of senior technicians in public health and epidemiological surveillance) of Parakou University was obtained for the study. All the data have been managed confidentially.

\section{Results}

A total of 380 respondents were investigated out of 385 hypertensive people identified.

\subsection{Characteristics of the Respondents}

The mean age was $52.4 \pm 16.5$ years with extremes of 
26 and 98 years. Sociodemographic and economic data are presented in the second column of table 1 . We noted a female predominance $(67.9 \%)$. The age group [40-54 years] was most represented (34.7\%). Nearly two-thirds of them had no school education $(62.6 \%)$. There were $38.4 \%$ of traders. Around $97.1 \%$ had a low monthly income $\leq 80$ USD (minimum salary in Benin).
Almost all the respondents (379/380) have heard of hypertension. The frequent sources of information were the TAHES project $(99.5 \%)$ and relatives $(15.5 \%)$. Among 380 surveyed, $11.1 \%$ were obese and $61.3 \%$ had raised blood pressure (systolic blood pressure $\geq 140$ $\mathrm{mmHg}$ or diastolic blood pressure $\geq 90 \mathrm{~mm} \mathrm{Hg}$ ) on the day of the survey.

Table 1. Link between socio-demographic factors and KAPs among respondents, Tanvè (Benin) 2018

\begin{tabular}{|c|c|c|c|c|c|c|c|}
\hline & \multirow{2}{*}{$\begin{array}{c}\text { Total }=\mathbf{3 8 0} \\
\mathrm{n}(\%)\end{array}$} & \multicolumn{2}{|c|}{ Good Knowledge } & \multicolumn{2}{|c|}{ Good attitudes } & \multicolumn{2}{|c|}{ Good practices } \\
\hline & & $\mathrm{n}(\%)$ & $\mathrm{p}$ & n (\%) & $\mathrm{p}$ & n (\%) & $\mathrm{p}$ \\
\hline Sex & & & 0.715 & & 0.850 & & 1.000 \\
\hline Male & $122(32.1)$ & $29(23.8)$ & & $110(90.2)$ & & $3(2.5)$ & \\
\hline Female & $258(67.9)$ & $57(22.1)$ & & $231(89.5)$ & & $7(2.7)$ & \\
\hline Age (years) & & & 0.252 & & & & 0.372 \\
\hline $25-39$ & $96(25.3)$ & $22(22.9)$ & & $84(87.5)$ & 0.287 & $1(1.0)$ & \\
\hline $40-54$ & $132(34.7)$ & $32(24.2)$ & & $121(91.7)$ & & $6(4.6)$ & \\
\hline $55-69$ & $86(22.6)$ & $23(26.7)$ & & $80(93.2)$ & & $1(1.2)$ & \\
\hline$\geq 70$ & $66(17.4)$ & $9(13.6)$ & & $56(84.9)$ & & $2(3.0)$ & \\
\hline Educational level & & & 0.986 & & 0.130 & & 0.277 \\
\hline No school education & $238(62.6)$ & $54(22.7)$ & & $215(90.9)$ & & $5(2.1)$ & \\
\hline literate & $39(10.3)$ & $9(23.1)$ & & $37(94.9)$ & & $1(2.6)$ & \\
\hline Primary & $66(17.4)$ & $14(22.2)$ & & $60(90.9)$ & & $4(6.1)$ & \\
\hline Secondary or university & $37(9.7)$ & $9(24.3)$ & & $29(78.4)$ & & $0(0.0)$ & \\
\hline Employment status & & & 0.104 & & 0.188 & & 0.795 \\
\hline Trader & $146(38.4)$ & $30(20.6)$ & & $131(89.7)$ & & $3(2.1)$ & \\
\hline Artisan/worker/peasant & $130(34.2)$ & $36(27.7)$ & & $120(92.3)$ & & $4(3.1)$ & \\
\hline Homemaker & $86(22.6)$ & $15(17.4)$ & & $76(88.4)$ & & $3(3.5)$ & \\
\hline Employed/Student & $18(4.8)$ & $7(38.9)$ & & $14(77.8)$ & & $0(0.0)$ & \\
\hline Monthly income (USD) & & & 0.468 & & 0.087 & & 0.950 \\
\hline$\leq 80$ & $369(97.1)$ & $85(23.0)$ & & $333(90.2)$ & & $10(2.7)$ & \\
\hline$>80$ & $11(2.9)$ & $1(9.1)$ & & $8(72.7)$ & & $0(0.0)$ & \\
\hline
\end{tabular}




\subsection{Knowledge and Attitudes of Respondents}

Data on hypertension knowledge among respondents are presented in table 2 . Headache $(71.1 \%)$ and dizziness (76.8\%) were the main symptoms cited by the respondents. Stress was recognized by $94.7 \%$ of them as a risk factor. The most cited complication was stroke or "paralysis of one side of the body" (96.3\%). Less than a twentieth had confirmed that hypertension was not communicable. The majority knew that hypertension is a long-term condition $(82.6 \%)$ and that it requires monitoring by a health worker $(92.4 \%)$. More than three-quarters did not know the maximum duration of action for antihypertensive drugs.

Among the 380 respondents, $86(22.6 \%)$ had a good level of knowledge towards hypertension. The mean score was $14.7 \pm 3.4$ with extremes of 4 and 21 .

Table 2. Evaluation of knowledge towards hypertension among respondents, Tanvè (Benin) 2018

\begin{tabular}{|c|c|c|}
\hline & Total $=380$ & $\%$ \\
\hline \multicolumn{3}{|l|}{ Symptoms } \\
\hline Headache & 270 & 71.1 \\
\hline Dizziness & 292 & 76.8 \\
\hline Ringing in the ears & 262 & 68.9 \\
\hline Visual blur & 264 & 69.5 \\
\hline Heaviness of the neck & 226 & 59.5 \\
\hline \multicolumn{3}{|l|}{ Risk factors } \\
\hline Low physical activity practice & 276 & 72.6 \\
\hline Excessive salt intake & 314 & 82.6 \\
\hline Fat diet & 323 & 85.0 \\
\hline Tobacco consumption & 109 & 28.7 \\
\hline Stress & 360 & 94.7 \\
\hline Obesity & 21 & 5.5 \\
\hline Diabetes & 180 & 47.4 \\
\hline Heredity & 64 & 16.8 \\
\hline \multicolumn{3}{|l|}{ Complications } \\
\hline Stroke ("Paralysis of one side of body") & 366 & 96.3 \\
\hline Kidney disease & 286 & 75.3 \\
\hline Heart failure & 260 & 68.4 \\
\hline blindness & 320 & 84.2 \\
\hline Non-traumatic foot amputation & 277 & 72.9 \\
\hline \multicolumn{3}{|l|}{ Other informations } \\
\hline Hypertension can be asymptomatic & 61 & 16.1 \\
\hline $\begin{array}{l}\text { Hypertension \{ XE "HTA:Hypertension } \\
\text { Artérielle" \}is not communicable }\end{array}$ & 5 & 1.3 \\
\hline $\begin{array}{l}\text { Hypertension is diagnosed by a device } \\
\text { placed on the arm \{ XE } \\
\text { "HTA:Hypertension Artérielle" }\}\end{array}$ & 377 & 99.2 \\
\hline Hypertension requires long-term treatment & 314 & 82.6 \\
\hline $\begin{array}{l}\text { Hypertension requires follow-up by a } \\
\text { health-worker }\end{array}$ & 351 & 92.4 \\
\hline $\begin{array}{l}\text { Maximum duration of anti-hypertensive } \\
\text { drug effect is } 24 \mathrm{~h}\end{array}$ & 3 & 0.8 \\
\hline
\end{tabular}

Data on attitudes towards hypertension among respondents are presented in table 3. Around 99.2\% of respondents considered that hypertension is a serious disease and that it is important to monitor blood pressure regularly (99.5\%). According to their opinion, compliance with hygiene rules can help blood pressure control. However, 97.6\% have declared that hypertension can be linked to a spell.

Among the 380 respondents, 341 (89.7\%) had good attitudes towards hypertension. The mean score was $5.9 \pm$ 0.6 with extremes of 1 and 8 .

\subsection{Practices of Respondents towards Hypertension}

Only half of the respondents $(50.1 \%)$ were aware of their status and stated that they had a history of raised blood pressure. Among them, 3.2\% also had a history of diabetes. Among the 191 respondents who knew they were hypertensive, $110(59.6 \%)$ were taking medication prescribed by a health worker. About half (53.4\%) of known and treated hypertensive regularly took their treatment.

Data on hypertension practices among respondents are presented in table 4 . Near a tenth of the respondents $(8.2 \%)$ smoked. About two-thirds of them (59.5\%) had an insufficient consumption of fruits and vegetables and a near a fifth $(16.3 \%)$ had a low physical activity practice. The majority did not have a health notebook $(93.7 \%)$ nor a follow-up appointment with a health worker (98.4\%).

Only $10(2.6 \%)$ had good practices towards hypertension in the sample. This frequency represented $5.2 \%$ of 191 hypertensive who knew their status. The mean score of practices was $5.7 \pm 1.6$ with extremes of 2 and 6.

\subsection{Link between Sociodemographic Factors and KAPs}

The study didn't show a significant association between sociodemographic factors and knowledge nor between sociodemographic factors and practices.

Table 3. Evaluation of attitudes towards hypertension among respondents, Tanvè (Benin) 2018

\begin{tabular}{|l|c|c|}
\hline & Total=380 & \% \\
\hline Hypertension is a serious condition & 377 & 99.2 \\
\hline Hypertension can be linked to a spell & 371 & 97.6 \\
\hline Hypertension can be favored by life style & 378 & 92.1 \\
\hline Blood pressure measurement is important & 370 & 99.5 \\
\hline $\begin{array}{l}\text { Compliance with hygiene rules prevents } \\
\text { hypertension }\end{array}$ & 376 & 97.4 \\
\hline $\begin{array}{l}\text { Compliance with hygiene rules contributes } \\
\text { to the control of blood pressure in patients }\end{array}$ & 367 & 98.9 \\
\hline $\begin{array}{l}\text { Regular use of antihypertensive drugs } \\
\text { normalizes blood pressure }\end{array}$ & 367 & 96.6 \\
\hline $\begin{array}{l}\text { It's important to continue treatment even } \\
\text { when the blood pressure is normalized }\end{array}$ & 17 & 4.5 \\
\hline
\end{tabular}


Table 4. Evaluation of practices towards hypertension, among respondents, Tanvè (Benin) 2018

\begin{tabular}{|c|c|c|}
\hline & Total $=380$ & $\%$ \\
\hline $\begin{array}{l}\text { Tobacco consumption ( } \geq 1 \text { cigarette } \\
\text { during } 12 \text { last months) }\end{array}$ & 31 & 8.2 \\
\hline $\begin{array}{l}\text { Low physical activity }(<150 \text { minutes } \\
\text { of moderate physical activity / day) }\end{array}$ & 62 & 16.3 \\
\hline $\begin{array}{l}\text { Low fruits and vegetables consumption } \\
(<5 \text { portions or } 400 \mathrm{~g} / \text { day })\end{array}$ & 226 & 59.5 \\
\hline $\begin{array}{l}\text { Excessive alcohol intake ( } \geq 2 \text { standard } \\
\text { drinks/ day) }\end{array}$ & 12 & 3.2 \\
\hline $\begin{array}{l}\text { Excessive soda consumption }(\geq 1 \\
\text { bottle or } 330 \mathrm{ml} \text { of soda/day) }\end{array}$ & 69 & 18.2 \\
\hline $\begin{array}{l}\text { Adding salt at the table in the meal } \\
\text { (often) }\end{array}$ & 260 & 68.4 \\
\hline Too salty meal consumption (often) & 352 & 92.6 \\
\hline $\begin{array}{l}\text { Irregular blood pressure measurement } \\
(<\text { twice / year) }\end{array}$ & 203 & 53.4 \\
\hline $\begin{array}{l}\text { Irregular follow-up by a health worker } \\
(<\text { once / year })\end{array}$ & 335 & 88.2 \\
\hline Lack of follow-up appointment & 374 & 98.4 \\
\hline Lack of health book & 356 & 93.7 \\
\hline $\begin{array}{l}\text { Irregular blood sugar measurement } \\
(<\text { once/year })\end{array}$ & 163 & 42.9 \\
\hline
\end{tabular}

\section{Discussion}

This study was carried out in rural area, in a sample of hypertensive patients of average age around 52 years and predominantly female. Overall, it shows low levels of knowledge and practices towards hypertension despite a good perception of the disease. It is difficult to compare the studies available on the KAPs in hypertensive patients between them because of the methodological differences and data variability. However, most data in the literature showed that whatever the approach used, the levels of knowledge and practices towards hypertension were not optimal [14-19].

The results agree with those previously observed in a rural peripheral health center of south-western Benin where only $21.9 \%$ of hypertensive patients had a good knowledge relating to their condition. Among the patients aware of their status, $54.8 \%$ didn't follow any dietetic measures and $74.1 \%$ didn't take medications [12]. Studies in Benin urban environments could show better results. A significant association between good knowledge relating to hypertension and urban residence has been noted in Ethiopia $[19,20]$.

Higher frequencies of good knowledge were estimated among hypertensive patients in a Nigerian rural hospital in $2014(47.1 \%)$ as well as in two specialized hospitals in Ethiopia in 2019 (48.6\% by Bacha et al. and $51.7 \%$ by Mekonnen et al.) [19-21]. On the other hand, lower frequency (14.0\%) was reported in Cameroon, among 221 hypertensive patients in the Bamenda health district in 2015 [22]. Similar studies in other regions showed various results from $25.2 \%$ in Iran, $41.2 \%$ in India, $62.0 \%$ in Pakistan, $69.9 \%$ in Sri-Lanka, to $82.3 \%$ in Brazil [23-27]. In USA, Oliveira et al. had reported in 2004 among 826 patients that most of them had good knowledge: $81.8 \%$ knew the meaning of the term of hypertension, $70.2 \%$ how dangerous hypertension is for health and $90.2 \%$ knew lowering high blood pressure would improve the health [28]. Almost all (91.2\%) were aware of their status [28]. Several reasons could explain the differences. People living in high income countries as the USA have higher levels of school education, more access to the media and health education program than those living in low income countries, which could improve their knowledge relating to hypertension.

High salt intake is widely known in our sample as hypertension risk factor. This finding suggests a good acceptability of possible interventions for salt reduction in the target population.

Contrary to this study, poor attitudes towards hypertension were noted among hypertensive patients by Bacha et al. in Ethiopia in 2019 (48.6\% in St Paul's hospital, Addis-Ababa) and by Bollampally et al. in India in 2016 (53.8\% in Ghandi hospital) [19, 24]. Positive attitudes towards life style modifications (99\%) were rather reported in Nigeria (Kano teaching hospital) in 2017 [29].

Regarding good practices, higher frequencies were estimated among hypertensive patients in hospital-based studies in Ethiopia (20.3\% and 49\%) and in India (41.2\%) $[14,15,29]$. Iloh et al. had reported low adherence of life style modification in Nigeria in 2014 (20.3\%) while Dejene and Rathore indicated the opposite in Ethiopia in $2017(61.4 \%)$ [30, 31].

We didn't find any link between socio-demographic factors and KAPs. A larger sample could show significant associations. A significant link between educational level and knowledge towards hypertension was described in other studies in Ethiopia and Iran [15, 17].

This study was carried out in community among hypertensive screened people, informed of the results of blood pressure measurements. Over half of them have uncontrolled blood pressure. These people had received advice, directives and even prescriptions. However, about $50 \%$ said they had no history of raised blood pressure. Communication on the result should be improved during hypertension screening campaigns. We observed higher proportion of smoking $(8.2 \%)$ than that reported in the general population in Benin (5\%) [11]. Health monitoring and taking medication were irregular in more than half of the respondents who recognized that they were hypertensive. This situation does not promote blood pressure control in these patients. In view of these results, it is necessary to conduct a continuous awareness of hypertensive patients and to provide them support (implementation of support group, patient associations) in the management of hypertension. The implementation of 
therapeutic education program appears relevant in the studied population.

This study fills the information gap on the KAPs among hypertensive screened in the TAHES cohort in rural area. It will allow setting up local adapted interventions to their behaviour change. The sample was recruited from the community; the assessment of knowledge was broader (based on 24 items) and concerned all the respondents.

The study is based on statements. Information bias (memorization bias, social desirability bias) may have influenced the results. However, they were downplayed by the standardization of questions and the neutrality of investigators who were not health workers.

\section{Conclusions}

This study shows a low level of knowledge relating to hypertension and inadequate practices for secondary prevention. Interventions aimed at providing correct information on hypertension and support to hypertensive patients for the adoption of good behaviours would be effective in the target population. These interventions could also be relevant among hypertensive patients in others African rural areas with similar characteristics.

\section{REFERENCES}

[1] World Health Organization. Global brief on hypertension [Online]. WHO 2013. [cited 17 Dec 2019]. Available from: http://www.who.int/cardiovascular_diseases/publications/gl obal_brief_hypertension/fr/

[2] Wang H, Naghavi M, Allen C, Barber RM, Bhutta ZA, Carter A, et al. Global, regional, and national life expectancy, all-cause mortality, and cause-specific mortality for 249 causes of death, 1980-2015: a systematic analysis for the Global Burden of Disease Study 2015. The Lancet. 2016;388(10053):1459-544.

[3] Beaney T, Schutte AE, Tomaszewski M, Ariti C, Burrell LM, Castillo RR, et al. May Measurement Month 2017: an analysis of blood pressure screening results worldwide. Lancet Glob Health. 2018;6(7): e736-43.

[4] World Health Organization. Questions-answers on hypertension [Online]. WHO 2015. [cited 17 Dec 2019]. Available from: www.who.int/features/qa/ $82 / \mathrm{fr} /$

[5] Chow CK, Teo KK, Rangarajan S, Islam S, Gupta R, Avezum A, et al. Prevalence, awareness, treatment, and control of hypertension in rural and urban communities in high-, middle-, and low-income countries. JAMA. 2013; 310(9): 959-68.

[6] Guwatudde D, Nankya-Mutyoba J, Kalyesubula R, Laurence C, Adebamowo C, Ajayi I, et al. The burden of hypertension in sub-Saharan Africa: a four-country cross sectional study. BMC Public Health. 2015;15:1211.

[7] Antignac M, Diop IB, Macquart de Terline D, Kramoh KE,
Balde DM, Dzudie A, et al. Socioeconomic Status and Hypertension Control in Sub-Saharan Africa: The Multination EIGHT Study (Evaluation of Hypertension in Sub-Saharan Africa). Hypertension. 2018;71(4):577-84.

[8] World health Organization regional office for Africa. The african health report 2014 [Online]. WHO 2016. [cited 7 oct 2019]. Available from: http://www.aho.afro.who.int/site s/default/files/publications/2446/ARHR-2014-fr.pdf

[9] Affangla D, Coumba G, Simo Wabo A, Dione M, kamadore T, Diop M, et al. Cardiovascular risk profile of the hypertensive patient in an outpatient clinic at the diabetes and cardiometabolic disease management center of Saint Jean de Dieu Hospital in Thiès. Cardiol Trop. 2016;(146):15-21.

[10] Sonou D, Lemone H, Adjagba P, Codjo L, Hounkponou M, Houehanou-Sonou $\mathrm{C}$, et al. Absolute cardiovascular risk and complications of hypertension in hypertensive patients at Cotonou (Benin). J Société Biol Clin Bénin. 2017;(26):35-40.

[11] Ministry of Health / National direction of public health / Non communicable disease National Program. Final report of STEPS survey in Benin [Online]. Ministry of health 2016. [cited 27 oct 2019]. available from: http://www.who.int/chp/steps/2008_STEPS_Report_Benin. pdf

[12] Adjagba P, Codjo LH, Sonou A, Gninkoun J, Hounkponou $\mathrm{M}$, Aguiya $\mathrm{J}$, et al. Knowledge, attitudes and practice on hypertension in patients of a primary healthcare center in the southwest of Benin. J Société Biol Clin. 2019;(30):6-11.

[13] Houehanou YC, Mizéhoun-Adissoda C, Amidou S, Désormais I, Houénassi M, Preux P-M, et al. Feasibility of a cardiovascular cohort in a Sub-Saharan Africa community: preliminary report of the pilot project TAHES (Tanvè Health Study) in Benin. Glob Health Action. 2017; 10(1): 1270528

[14] Ademe S, Aga F, Gela D. Hypertension self-care practice and associated factors among patients in public health facilities of Dessie town, Ethiopia. BMC Health Serv Res. 2019;19(1):51.

[15] Gebremichael GB, Berhe KK, Beyene BG, Gebrekidan KB. Self-care practices and associated factors among adult hypertensive patients in Ayder Comprehensive Specialized Hospital, Tigray, Ethiopia, 2018. BMC Res Notes. 2019; 12(1): 489 .

[16] Chimberengwa PT, Naidoo M, cooperative inquiry group. Knowledge, attitudes and practices related to hypertension among residents of a disadvantaged rural community in southern Zimbabwe. PloS One. 2019;14(6):e0215500.

[17] Rashidi Y, Manaflouyan H, Pournaghi Azar F, Nikniaz Z, Nikniaz L, Ghaffari S. Knowledge, attitude and practice of Iranian hypertensive patients regarding hypertension. J Cardiovasc Thorac Res. 2018; 10(1): 14-9.

[18] Familoni OB, Ariba AJ. Ability of Nigerian hypertensive patients to perceive changes in their blood pressure. Cardiovasc J South Afr off J South Afr Card Soc South Afr Soc Card Pract. 2003; 14(4):195-8.

[19] Bacha D, Abera H. Knowledge, Attitude and Self-Care Practice towards Control of Hypertension among 
Hypertensive Patients on Follow-up at St. Paul's Hospital, Addis Ababa. Ethiop J Health Sci. 2019; 29(4):421-30.

[20] Mekonnen CK, Mekonnen BY, Mekonnen HS. Knowledge and Associated Factors of Blood Pressure Control Among Hypertensive Patients Attending Chronic Illness Follow-Up Clinic at University of Gondar, Comprehensive Specialized Hospital, Northwest, Ethiopia. Vascular health and risk management. 2019; 15: 551-8

[21] Adesola Busari O. Prescribing Pattern and Utilization of Antihypertensive Drugs and Blood Pressure Control in Adult Patients with Systemic Hypertension in a Rural Tertiary Hospital in Nigeria. AJIM. 2014;2(6):144.

[22] Akoko BM, Fon PN, Ngu RC, Ngu KB. Knowledge of Hypertension and Compliance with Therapy Among Hypertensive Patients in the Bamenda Health District of Cameroon: A Cross-sectional Study. Cardiol Ther. 2017; 6(1): 53-67.

[23] Zinat Motlagh SF, Chaman R, Ghafari SR, Parisay Z, Golabi MR, Eslami AA, et al. Knowledge, Treatment, Control, and Risk Factors for Hypertension among Adults in Southern Iran. Int J Hypertens.2015; 2015: 897070.

[24] Bollampally M, Chandershekhar P, Kumar KP, Surakasula A, Srikanth S, Reddy TRM. Assessment of patient's knowledge, attitude and practice regarding hypertension. International Journal of Research in Medical Sciences. 2017;4(8):3299-304.

[25] Nadeem MK, Mari A, Iftikhar S, Khatri A, Sarwar T, Patel MJ. Hypertension-related Knowledge and Its Relationship with Blood Pressure Control in Hypertensive Patients Visiting a Semi-private Tertiary-care Charity Hospital in Karachi, Pakistan. Cureus. 2019;11(10):e5986.

[26] Pirasath S, Kumanan T, Guruparan M. A Study on Knowledge, Awareness, and Medication Adherence in Patients with Hypertension from a Tertiary Care Centre from Northern Sri Lanka. Int J Hypertens.2017;2017:96564 50.

[27] Barreto M da S, Reiners AAO, Marcon SS. Knowledge about hypertension and factors associated with the non-adherence to drug therapy. Rev Lat Am Enfermagem. 2014;22(3):491-8

[28] Oliveria SA, Chen RS, McCarthy BD, Davis CC, Hill MN. Hypertension knowledge, awareness, and attitudes in a hypertensive population. J Gen Intern Med. 2005; 20(3): 219-25.

[29] Hadiza S, Yakasai AM, Yau JA, Adamu FI, Mijinyawa MS. Factor analysis of knowledge, attitude and practice of life style modification measures among hypertensive patients in North - Western Nigeria. J Med Res. 2017; 3(2): 74-8.

[30] Iloh GUP, Amadi AN, Okafor GOC, Ikwudinma AO, Odu FU, Godswill-Uko EU. Adherence to Lifestyle Modifications among Adult Hypertensive Nigerians with Essential Hypertension in a Primary Care Clinic of a Tertiary Hospital in Resource-poor Environment of Eastern Nigeria. Journal of Advances in Medicine and Medical Research. 2014; 4(18), 3478-3490.

[31] Dejene D, Rathore KS. Assessment of Knowledge, Attitude and Practice of Hypertensive Patients towards the NonMedical Management of Hypertension in Bishoftu General
Hospital, 2016. The Pharmaceutical and Chemical Journal. 2017; 4(1): 48-59. 